Vanishing Acts 
This page intentionally left blank 


\section{Vanishing Acts}

THEATER SINCE THE SIXTIES

Gordon Rogoff

YALE UNIVERSITY PRESS NEW HAVEN AND LONDON 